\title{
Stapler vs. hand-sewn intrathoracic esophagogastric anastomosis: which anastomotic method renders better results?
}

\author{
Theodoros Kolokotronis ${ }^{1}$, Michail Galanis ${ }^{2}$ \\ ${ }^{1}$ Clinic for surgery \& center for minimal invasive surgery, Evang. Kliniken Essen-Mitte, Essen 45136, Germany. \\ ${ }^{2}$ Clinic for general, visceral, thorax, pediatric and endocrine surgery, University Hospital Johannes Wesling Minden, Minden \\ 32429, Germany.
}

Correspondence to: Dr. Theodoros Kolokotronis, Clinic for surgery \& center for minimal invasive surgery, Evang. Kliniken EssenMitte, Henricistr. 92, Essen 45136, Germany. E-mail: fernado13984@yahoo.gr

How to cite this article: Kolokotronis T, Galanis M. Stapler vs. hand-sewn intrathoracic esophagogastric anastomosis: which anastomotic method renders better results? Mini-invasive Surg 2021;5:19. https://dx.doi.org/10.20517/2574-1225.2021.07

Received: 17 Jan 2021 First Decision: 19 Feb 2021 Revised: 27 Feb 2021 Accepted: 18 Mar 2021 Published: 23 Apr 2021

Academic Editor: Noriyoshi Sawabata Copy Editor: Yue-Yue Zhang Production Editor: Yue-Yue Zhang

\begin{abstract}
Aim: We investigated the impact of the anastomotic method in the frame of open abdominothoracic esophageal resection (hand-sewn vs. stapler anastomosis) in patients with carcinoma submitted to surgery in the University Clinic of Saarland over a 14-year period.
\end{abstract}

Methods: In total, 176 patients underwent an abdominothoracic resection with intrathoracic anastomosis and conventional gastric conduit formation; two groups of patients were analyzed: end-to-end, hand-sewn anastomosis (Group 1) and end-to-side, circular stapler anastomosis (Group 2). Both groups were compared regarding anastomotic leaks and strictures, postoperative morbidity, 90-day mortality and survival.

Results: The rates of anastomotic leak and stricture in the stapler group were reduced in comparison to hand-sewn group, however without reaching statistical significance ( $8 \%$ vs. $13.5 \%, P=0.22$, and $6 \%$ vs. $13.5 \%, P=0.1$, respectively). In contrast, the rates of redo surgery $(34.1 \%$ vs. $8 \%, P=0.001)$ and 90 -day mortality $(11.9 \%$ vs. $2 \%$, $P=0.02$ ) were significantly higher in the hand-sewn anastomosis group.

Conclusion: The management of anastomotic leak (stent insertion vs. reoperation) combined with the use of stapler to perform intrathoracic esophagogastric anastomosis improved the postoperative outcome after abdominothoracic esophageal resection. 
Keywords: Esophagogastric anastomosis, circular stapler, Clavien-Dindo classification, anastomotic leak, gastric tube, esophagectomy, esophageal resection, Ivor-Lewis esophagectomy

\section{INTRODUCTION}

Esophageal cancer is a severe disease with poor prognosis. The reconstruction of alimentary tract after esophageal resection remains a challenge, with anastomotic leak being a main reason for major postoperative morbidity after abdominothoracic esophagectomy. The incidence of anastomotic leak varies from $0 \%$ to $24 \%{ }^{[1-4]}$, leading to higher rates of postoperative morbidity and mortality ${ }^{[5]}$. Various factors have been suggested to promote anastomotic leak, including patient-related characteristics ${ }^{[6,7]}$, perioperative factors $^{[8]}$ and surgical technique (undo tension on the anastomosis, technical failures, adequacy of blood supply of both organs at the connection site $e^{[9]}$ and location of the esophagogastric anastomosis ${ }^{[10]}$ ). Controversy remains about the optimal location of esophagogastric anastomosis (intrathoracic vs. cervical). Intrathoracic esophagogastric anastomosis has been associated with lower anastomotic leak rate, lower rate of recurrent nerve paresis and shorter hospital stay than a cervical anastomosis ${ }^{[6,10,1]}$. However, three randomized controlled trials could not show statistical difference in anastomotic leak rate between intrathoracic and cervical location ${ }^{[12-14]}$. Advantages of cervical anastomosis include wider oncologic resection margin and less devastating complications compared with intrathoracic anastomosis (risk of mediastinitis and esophagobronchial fistula). A potential solution to manage the challenge of intrathoracic esophagogastric anastomosis could be the use of a stapler device to perform the anastomosis; therefore, we focused on this topic of paramount importance in the present study. Since the first use of stapler anastomosis in $1979^{[15]}$, there have been several reports supporting its use in order to reduce the rate of anastomotic leak ${ }^{[16,1]]}$. Further technical variations, including the use of linear stapler to perform semimechanical intrathoracic anastomosis, have also been suggested to reduce postoperative anastomotic leak rate $^{[18]}$. We investigated the impact of anastomotic method (hand-sewn $v s$. circular stapler) on anastomotic leak rate in patients with esophageal carcinoma submitted to intrathoracic esophagogastric anastomosis in the University Clinic of Saarland during a 14-year period.

\section{METHODS}

We performed a retrospective, non-randomized study to investigate which anastomotic method rendered better results. Our study population consisted of 176 patients with esophageal carcinoma, with intrathoracic anastomosis after abdominothoracic resection. We performed an Ivor-Lewis abdominothoracic esophageal resection, consisting of a median laparotomy, mobilization of the stomach and preparation of a conventional gastric tube. Simultaneous cholecystectomy was routinely performed ${ }^{[19]}$. The gastric conduits were performed conventionally ${ }^{[20]}$ (three patients submitted to fundus rotation gastroplasty to achieve longer gastric conduit and better blood supply ${ }^{[9]}$ were excluded). For conventional tube formation, the lesser curvature with the vessel arcade was resected with linear stapler ${ }^{[21]}$. The right gastric and gastroepiploic vessels provide the blood supply of the gastric conduit. A right anterolateral thoracotomy was performed, and the esophageal resection was performed in the level of azygos vein. D2 lymphadenectomy was routinely performed. Patients were divided into two groups: Group 1 received hand-sewn, double row, end-to-end anastomosis using 4-0 PDS and 5-0 PDS stitches and Group 2 received single row end-to-side, stapler anastomosis using a $25-\mathrm{mm}$ circular stapler. The type of anastomosis was selected upon surgeon's preference. Anastomosis was mainly performed as hand-sewn from 2001 to 2012 and changed to a stapler anastomosis routinely using the $25-\mathrm{mm}$ circular intraluminal stapler (Covidien, EEA, DST Series). Operations were only performed by chief or experienced senior surgeons. 
Both groups were compared regarding anastomotic leaks and strictures, postoperative morbidity, 90-day mortality and survival.

To assess the severity of perioperative morbidity, the Clavien-Dindo classification was used ${ }^{[22]}$; the overall postoperative morbidity during first hospital stay (surgical and respiratory complications included) was divided into minor morbidity, corresponding to Clavien-Dindo Grades I-II, and major/lethal postoperative morbidity corresponding to Clavien-Dindo Grades III-V. The group of minor postoperative morbidity consisted of complications treated conservatively. The group of major postoperative morbidity consisted of complications requiring surgical, endoscopic or radiological intervention (Clavien-Dindo Grade III); lifethreatening complications requiring ICU management (Grade IV); and lethal complications (Grade V). The mortality during the first hospital stay was divided into 30-, 60- and 90-day mortality.

The disruption of the anastomosis leading to extravasation of intraluminal content was defined as anastomotic leak. The definite diagnosis of anastomotic leak was confirmed endoscopically. Data collection and analysis were performed only on patients who underwent an intrathoracic anastomosis.

Anastomotic stricture was defined as dysphagia in the 6-month endoscopic control requiring intervention (endoscopic dilatation). Patients with anastomotic stricture suffered from Clavien-Dindo Grade III complication.

\section{Tumor management}

Endoscopy was performed preoperatively as well as 6 months postoperatively to exclude tumor recurrence. In the preoperative work-up, a computed tomography was performed to detect further organ metastases. Neoadjuvant therapy was carried out preoperatively according to the international guidelines ${ }^{[23]}$. Surgical resection followed 4-6 weeks after the end of the neoadjuvant therapy. Until 2012, we used the PLF scheme, based on cisplatin, folic acid, 5-fluoruracil and simultaneous irradiation [45 Gy (1.5 Gy per day)] in cases of squamous-cell esophageal carcinoma. Since 2012, we have performed neoadjuvant chemoradiation, as proposed by the Dutch CROSS trial, consisting of weekly administration of carboplatin und paclitaxel for 5 weeks and concurrent radiotherapy (41.4 Gy in 23 fractions) followed by surgery 4-6 weeks later. Cardiopulmonary examinations (electrocardiogram, echocardiogram and lung function test) were performed preoperatively.

\section{Perioperative treatment}

Patients received single-shot antibiotics intraoperatively. This included metronidazole $500 \mathrm{mg}$ i.v. and ceftriaxone $2 \mathrm{~g}$ i.v. In the case of penicillin allergy, clindamycin $600 \mathrm{mg}$ i.v. was injected. After confirmation of a patent anastomosis-using radiographic control-on Postoperative Day 5, the nasogastric tube was routinely removed. Then, enteral feeding including liquids was started.

\section{Statistical analysis}

Statistical analysis was performed using $\chi^{2}$ test (chi square test), binary logistic regression and MannWhitney $U$ test. Survival data were recorded contacting either the Cancer Registry of Saarland or the house physicians. A 6-month follow-up was routinely performed including endoscopy. Log rank test and Cox regression were performed for survival analysis. Statistical analysis was conducted using IBM SPSS Statistics V22.0 (SPSS, Inc., Chicago, IL, USA). 


\section{RESULTS}

\section{Patient characteristics, operative data and postoperative outcome}

Overall, $126(71.6 \%)$ patients (Group 1) received a hand-sewn anastomosis, while 50 (28.4\%) patients (Group 2) received a stapler anastomosis. Patient characteristics were similar in both groups [Table 1]. Median age of patients at the time of surgery was 61 years (34-88 years), with a male-to-female ratio of 153:23. Fifty-two (29.5\%) patients were diagnosed with squamous-cell esophageal cancer, and 124 (70.5\%) patients with esophageal adenocarcinoma. Forty-five (25.6\%) patients had chronic obstructive pulmonary disease (COPD) at the time of surgery, $33(18.9 \%)$ patients coronary heart disease (CHD) and $34(19.3 \%)$ patients were obese. The preoperative rates of COPD $(P=0.13)$, CHD $(P=0.20)$ and obesity $(P=0.42)$ were not significantly different between the groups. In total, 93 (52.8\%) patients were admitted to neoadjuvant therapy due to preoperative staging (Group 1: $47.6 \% v \mathcal{~ s . ~ G r o u p ~ 2 : ~ 6 6 \% , ~} P=0.11$ ).

Median duration of surgery was $269 \mathrm{~min}$ (128-532 min), whereas the median intraoperative blood loss was $300 \mathrm{~mL}$ (5-4000 mL), as shown in Table 2. The median harvest of dissected lymph nodes was 17 (3-62).

Minor postoperative complications (Clavien-Dindo Grades I-II) were presented in 23 (13\%) patients. Major postoperative complications (Clavien-Dindo Grades III-IV) appeared in 29 (16.5\%) patients. Thirteen (10.3\%) patients in Group 1 and $10(20 \%)$ patients in Group 2 suffered from minor complications, whereas $25(19.8 \%)$ patients in Group 1 and 4 (8\%) patients in Group 2 suffered from major complications [Table 2]. More specifically, in Group 1, the distribution of minor complications was as follows: 2 (0.015\%) patients with wound infection, $3(0.02 \%)$ with chyle leak, $3(0.02 \%)$ with pneumonia and $5(0.04 \%)$ with pleural effusion. In Group 2, the distribution of minor complications was as follows: 1 (0.02\%) patient with wound infection, $1(0.02 \%)$ with chyle leak, $4(8 \%)$ with pneumonia, $6(0.06 \%)$ with pleural effusion and 1 (0.02\%) with pneumothorax. The distribution of major complications in Group 1 was as follows: 4 (0.03\%) patients with anastomotic leak, $4(0.03 \%)$ with anastomotic leak and simultaneous gastric conduit necrosis, $5(0.04 \%)$ with anastomotic leak and concomitant mediastinitis, 5 (0.04\%) with anastomotic leak and respiratory insufficiency, $1(0.008 \%)$ patient with bile leak, $1(0.008 \%)$ with early hiatal hernia, $3(0.02 \%)$ with wound dehiscence and $2(0.015 \%)$ with chyle leak needing reoperation. There were $4(8 \%)$ patients with anastomotic leak in the stapler anastomosis group. Eighteen (10.2\%) patients suffered from lethal postoperative complication (Clavien-Dindo Grade V) within 90 days after surgery. There were no significant differences between both groups concerning the incidence of minor and major morbidity, however the 90-day mortality was higher in the hand-sewn anastomosis group $(P=0.02$, Table 2$)$.

Minor surgical complications included wound infection and chyle leak treated conservatively, while minor cardiopulmonary complications included pleura effusion treated with diuretics, pneumothorax with no need for draining tube, pneumonia and atrial fibrillation. The minor postoperative morbidity did not differ significantly between the groups $(P=0.2)$. Major surgical complications included necrosis of gastric conduit enterothorax, hiatal hernia, anastomotic leak, wound dehiscence, bile leak (occurring in one patient in the frame of prophylactic cholecystectomy) and chyle leak with need for reoperation. Surgical complications (anastomotic leak and necrosis of the gastric conduit) led predominantly to major and lethal postoperative morbidity (Clavien-Dindo Grades III-V).

Forty-seven (26.7\%) patients were subjected to redo surgery during the first hospital stay. The rate of reoperations differed substantially between both groups (Group 1: $34.1 \%$ vs. Group 2: $8 \%, P=0.001$ ). The incidence of anastomotic leak was $12.5 \%(22 / 176)$ and did not differ significantly between the groups (Group 1: $14.3 \%$ vs. Group 2: $8 \%, P=0.22$ ), although it was almost $50 \%$ reduced in the stapler anastomosis group. The median hospital stay was 20 days (9-198 days) and did not significantly differ between the 
Table 1. Esophagectomies with intrathoracic anastomosis for esophageal cancer $(n=176)$ : patient characteristics

\begin{tabular}{lllll}
\hline Characteristic & Hand-sewn & Stapler & Total & P value \\
\hline Age in years, median [min, max] & $\mathbf{1 2 6}$ & $\mathbf{5 0}$ & $\mathbf{1 7 6}$ & 0.34 \\
Men/women ratio $n$ (\%) & $62[42,88]$ & $61[34,84]$ & $61[34,84]$ & 0.23 \\
Adenocarcinoma of esophagus $n$ (\%) & $111 / 15(88 \% / 12 \%)$ & $42 / 8(84 \% / 16 \%)$ & $153 / 23(86.9 \% / 13.1 \%)$ & 0.21 \\
Squamous-cell carcinoma of esophagus n (\%) & $86(68.3 \%)$ & $38(76 \%)$ & $124(70.5 \%)$ & 0.21 \\
COPD (\%) & $40(31.7 \%)$ & $12(24 \%)$ & $52(29.5 \%)$ & 0.13 \\
Coronary heart disease $n$ (\%) & $35(27.8 \%)$ & $10(20 \%)$ & $45(25.6 \%)$ & 0.20 \\
Obesity $n$ (\%) & $26(20.6 \%)$ & $7(14 \%)$ & $33(18.9 \%)$ & 0.42 \\
Neoadjuvant therapy $n$ (\%) & $24(19 \%)$ & $10(20 \%)$ & $34(19.3 \%)$ & 0.11 \\
\hline
\end{tabular}

Chi-square and Mann-Whitney $U$ tests were respectively used.

Table 2. Esophagectomies with intrathoracic anastomosis for esophageal cancer $(n=176)$ : operative data and postoperative outcome

\begin{tabular}{|c|c|c|c|c|}
\hline Parameters & $\begin{array}{l}\text { Hand-sewn } \\
126\end{array}$ & $\begin{array}{l}\text { Stapler } \\
50\end{array}$ & $\begin{array}{l}\text { Total } \\
176\end{array}$ & P value \\
\hline Duration of surgical procedure median [min, $\max ]$ & $280[128,532]$ & $261[160,376]$ & $269[128,532]$ & 0.49 \\
\hline Blood loss in $\mathrm{mL}$ median [min, max] & $300[50,4000]$ & $200[5,1500]$ & $300[5,4000]$ & 0.12 \\
\hline Number of dissected lymph nodes, median [min, max] & $17[3,62]$ & $17[6,34]$ & $17[3,62]$ & 0.59 \\
\hline $\begin{array}{l}\text { Minor postoperative complications } \\
\text { Clavien-Dindo Grade I-II, } n(\%)\end{array}$ & $13(10.3 \%)$ & $10(20 \%)$ & $23(13 \%)$ & 0.2 \\
\hline $\begin{array}{l}\text { Major postoperative complications } \\
\text { Clavien-Dindo Grade III-IV, } n(\%)\end{array}$ & $25(19.8 \%)$ & $4(8 \%)$ & $29(16.5 \%)$ & 0.12 \\
\hline Reoperation, $n(\%)$ & $43(34.1 \%)$ & $4(8 \%)$ & $47(26.7 \%)$ & $0.001^{\star \star \star}$ \\
\hline Respiratory complications, $n$ (\%) & $35(27.8 \%)$ & $12(24 \%)$ & $47(26.3 \%)$ & 0.36 \\
\hline Anastomotic leak, n (\%) & $18(14.3 \%)$ & $4(8 \%)$ & $22(12.5 \%)$ & 0.22 \\
\hline Anastomotic stricture, $n(\%)$ & $17(13.5 \%)$ & $3(6 \%)$ & $20(11.4 \%)$ & 0.1 \\
\hline 30-day mortality, $n$ (\%) & $6(4.8 \%)$ & $0(0 \%)$ & $6(4.8 \%)$ & 0.13 \\
\hline 60-day mortality, $n$ (\%) & $12(9.6 \%)$ & $1(2 \%)$ & $13(7.4 \%)$ & 0.08 \\
\hline 90-day mortality, n (\%) & $17(13.5 \%)$ & $1(2 \%)$ & $18(10.2 \%)$ & $0.02^{\star}$ \\
\hline Hospital stay in days, median [min, max] & $21[9,198]$ & $18[12,114]$ & $20[9,198]$ & 0.26 \\
\hline
\end{tabular}

${ }^{\star} P<0.05,{ }^{* \star \star} P<0.001 ;$ Chi-square and Mann-Whitney $U$ tests were respectively used.

groups $(P=0.26)$. The rate of anastomotic stricture in the 6-month follow-up did not significantly differ between the groups (Group 1: 13.5\% vs. Group 2: 6\%, $P=0.1$ ), although it was more than $50 \%$ reduced in the stapler group. The 30-, 60- and 90-day mortality was $4.8 \%(n=6), 7.4 \%(n=13)$ and $10.2 \%(n=18)$, respectively. The 90-day mortality was significantly lower in Group 2 (Group 1: 13.5\% vs. Group 2: 2\%, $P=$ 0.02). The most apparent differences of surgical outcome when comparing the anastomotic methods were the rate of reoperation and consequently the 90 -day mortality [Table 2].

\section{Management of anastomotic leak}

In the stapler anastomosis group, anastomotic leaks were treated with endoscopic stent insertion: 4 out of 50 (8\%) patients after stapler anastomosis suffered from anastomotic leak, of whom only one was subjected to new surgical procedure and 3 were successfully treated with endoscopic stent insertion. In contrast, in the hand-sewn anastomosis group, anastomotic leaks were predominantly treated with reoperation: 18 patients after hand-sewn anastomosis suffered from anastomotic leak, of whom 14 underwent new surgical procedure and 4 were treated with endoscopic stent insertion. Consequently, 90-day mortality (Clavien- 
Dindo Grade V complications) and overall survival were statistically significantly different between the groups of patients.

\section{Risk factors for major and lethal postoperative complications (Clavien-Dindo Grades III-V) after abdominothoracic esophageal resection}

The type of anastomosis $(P=0.004)$ and duration of surgery $(P=0.002)$ significantly influenced the incidence of major and lethal postoperative complications (Clavien-Dindo Grades III-V) in the multivariate analysis (binary logistic regression, Table 3).

\section{Survival}

Overall median patient survival was 18 months (0-121 months). In Group 1, the median survival was 16 months [minimum: 0; maximum: 119; mean: 31; Standard Deviation (SD): 32], whereas, in Group 2, the median survival was 22 months (minimum: 1; maximum: 121; mean: 20; SD: 18). Patients subjected to hand-sewn anastomosis experienced worse overall survival, as did patients with advanced UICC tumor stage ( $P=0.001$ and $P=0.002$, respectively, log rank test), as shown in Table 4 and Figure 1 . No significant differences were observed between UICC tumor staging and anastomotic technique $(P=0.355)$ or between histological type and anastomotic technique $(P=0.175)$.

In the multivariate analysis, the type of anastomosis and advanced UICC tumor stage were independent factors that significantly influenced overall survival [Table 5 and Figure 2].

\section{DISCUSSION}

In the present study, we focused on the impact of anastomotic method (intrathoracic stapler $v s$. hand-sewn esophagogastric anastomosis) on surgical outcome after abdominothoracic esophagectomy for cancer. Our data suggest that the management of anastomotic leak (endoscopic stent insertion vs. reoperation), combined with the use of stapler to perform intrathoracic esophagogastric anastomosis, positively influences postoperative morbidity, mortality and overall survival.

Regarding anastomotic leak rates after abdominothoracic esophageal resection, our incidence of $12.5 \%$ is similar to other reported rates. Major/lethal postoperative complications (Clavien-Dindo Grades III-V) were significantly lower in the stapler anastomosis group, obviously due to the lower reoperation rate. It is important to note that, in the hand-sewn anastomosis group, anastomotic leaks were treated with new surgical procedure (14 out of 18 patients with anastomotic leak), contrary to the stapler anastomosis group, thus leading to higher mortality (34.1\% reoperation and $13.5 \%$ Clavien-Dindo Grade V complications in the hand-sewn anastomosis group, compared to $8 \%$ and $2 \%$ in the stapler group, respectively). In the same line of evidence, no patient died from anastomotic leak in the stapler anastomosis group due to successful treatment with endoscopic stent insertion. This fact implies that the aggressive management of anastomotic leaks with redo surgery in the hand-sewn anastomosis group significantly worsened the postoperative outcome. In addition, we cannot exclude that the change of the intrathoracic anastomosis method (end-toend $v$ s. end-to-side) may have influenced the postoperative outcome, as the end of the gastric conduit is the most ischemic part. However, the intrathoracic esophagogastric anastomosis was performed in the height of azygos vein; the tension of the anastomosis is not so high; and the risk of gastric conduit ischemia is lower compared to, for example, in a cervical esophagogastric anastomosis. Therefore, it remains unclear whether the manner of anastomosis substantially influenced the incidence of anastomotic leaks. Moreover, the esophagogastric anastomosis was sewn from 2001 to 2012, and stapled anastomosis predominated thereafter; the era effect cannot be estimated in the significant improvement in outcomes. Both intraoperative blood loss and duration of surgery were comparable between the groups, but lower in the stapler group, in accordance with the results of other observational studies claiming that stapler anastomosis 
Table 3. Univariate and multivariate analysis of predictors of major postoperative complications (Clavien-Dindo III-IV) after resection for esophageal cancer

\begin{tabular}{|c|c|c|c|c|}
\hline \multirow{2}{*}{ Parameter } & \multicolumn{2}{|c|}{ Univariate analysis } & \multicolumn{2}{|c|}{ Multivariate analysis } \\
\hline & OR $(95 \% \mathrm{Cl})$ & $P$ value & OR $(95 \% \mathrm{Cl})$ & P value \\
\hline Age & $1.022(0.998-1.057)$ & 0.200 & & \\
\hline Sex & $1.745(0.703-4.331)$ & 0.230 & & \\
\hline $\mathrm{CHD}$ & $1.847(0.838-4.071)$ & 0.130 & & \\
\hline COPD & $1.633(0.802-3.327)$ & 0.180 & & \\
\hline Obesity & $1.057(0.465-2.403)$ & 0.900 & & \\
\hline Neoadjuvant therapy & $0.984(0.486-1.993)$ & 0.964 & & \\
\hline Duration of surgery & $0.992(0.987-0.997)$ & $0.003^{\star \star}$ & $0.991(0.986-0.997)$ & $0.002^{\star \star}$ \\
\hline Type of anastomosis (hand-sewn vs. stapler) & $3.296(1.369-7.937)$ & $0.008^{\star \star}$ & $3.666(1.499-8.963)$ & $0.004^{\star \star}$ \\
\hline Intraoperative blood loss & $1.000(0.999-1.001)$ & 0.68 & & \\
\hline
\end{tabular}

${ }^{\star \star} P<0.01$. OR: Odds ratio; Cl: confidence interval; CHD: coronary heart disease; COPD: chronic obstructive pulmonary disease.

Table 4. Risk factors for worse overall survival after abdomino-thoracic resection with intrathoracic anastomosis for esophageal cancer-univariate analysis

\begin{tabular}{|c|c|c|c|c|}
\hline \multirow[t]{2}{*}{ Parameter } & \multicolumn{2}{|c|}{$\begin{array}{l}\text { Log rank for categorical } \\
\text { parameters }\end{array}$} & \multicolumn{2}{|c|}{$\begin{array}{l}\text { Cox regression for continuous } \\
\text { parameters }\end{array}$} \\
\hline & $P$ value & $\chi^{2}$ & OR $(95 \% \mathrm{Cl})$ & P value \\
\hline Age & & & $1.07(0.997-1.036)$ & 0.098 \\
\hline Sex & 0.528 & 0.398 & & \\
\hline $\mathrm{CHD}$ & 0.950 & 0.004 & & \\
\hline COPD & 0.153 & 2.039 & & \\
\hline Obesity & 0.118 & 2.446 & & \\
\hline Neoadjuvant therapy & 0.060 & 3.595 & & \\
\hline Duration of surgery & & & $1.002(0.999-1.004)$ & 0.197 \\
\hline Type of anastomosis (hand-sewn vs. stapler) & $0.001^{\star \star \star}$ & 22.866 & & \\
\hline Anastomotic leak & 0.790 & 0.070 & & \\
\hline Reoperation & 0.150 & 2.108 & & \\
\hline Intraoperative blood loss & & & $1.000(0.999-1.000)$ & 0.658 \\
\hline $\begin{array}{l}\text { Minor postoperative complication (Clavien-Dindo I- } \\
\text { II) }\end{array}$ & 0.810 & 1.060 & & \\
\hline $\begin{array}{l}\text { Major postoperative complication (Clavien-Dindo III- } \\
\text { V) }\end{array}$ & 0.100 & 0.001 & & \\
\hline Histology (SCC vs. adenocarcinoma) & 0.310 & 1.034 & & \\
\hline UICC tumor stage & $0.002^{\star \star}$ & 16.971 & & \\
\hline
\end{tabular}

${ }^{* \star P} P<0.01,{ }^{* \star *} P<0.001$. OR: Odds ratio; $\mathrm{Cl}$ : confidence interval; CHD: coronary heart disease; COPD: chronic obstructive pulmonary disease; SCC: squamous cell carcinoma; UICC: Union international contre le cancer.

is faster than hand-sewn anastomosis ${ }^{[24]}$.

There are numerous other studies comparing hand-sewn with stapled esophagogastric anastomosis. The majority consist in retrospective, non-randomized studies. Primary end points in these studies were anastomotic leak and stricture rate. The reported results are not unanimous. Several reports showed no difference in anastomotic leak comparing both anastomotic methods, while other reports demonstrated decreased anastomotic leaks with stapler anastomosis. Kim et al. ${ }^{[2]}$ concluded in their systematic review of eight randomized, controlled trials that there was no significant difference in the anastomotic leak or early 
Table 5. Risk factors for survival after abdomino-thoracic resection for esophageal cancer-multivariate analysis

\begin{tabular}{lll}
\hline \multirow{2}{*}{ Parameter } & \multicolumn{2}{c}{ Cox regression } \\
\cline { 2 - 3 } & OR $\mathbf{( 9 5 \% \mathbf { C l } )}$ & P value \\
\hline Type of anastomosis & $0.165(0.067-0.409)$ & $<\mathbf{0 . 0 0 1}^{\star \star \star}$ \\
UICC tumor stage & $1.371(1.130-1.663)$ & $\mathbf{0 . 0 0 1 ^ { \star \star \star }}$ \\
\hline
\end{tabular}

***P < 0.001. OR: Odds ratio; Cl: confidence interval; UICC: Union international contre le cancer.

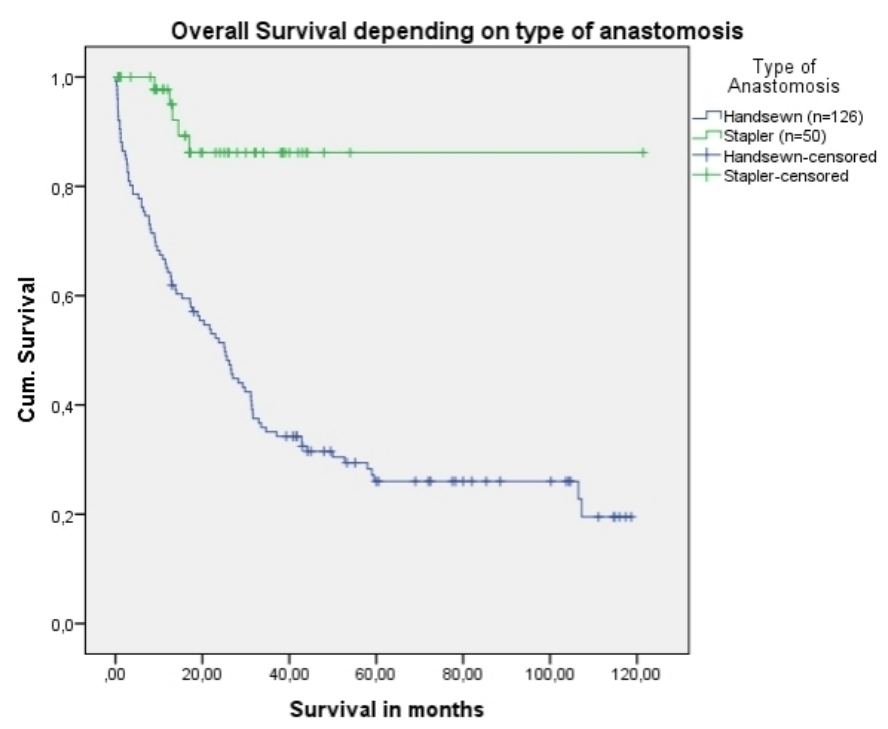

Figure 1. Cumulative survival after abdomino-thoracic resection with intrathoracic anastomosis for esophageal cancer depending upon the type of anastomosis $(P<0.001$, log rank test).

mortality between the anastomotic methods. One study demonstrated a difference in stricture rates, with fewer after hand-sewn anastomosis $(9 \% v s .40 \%, P=0.003)^{[25]}$. Two meta-analyses found no significant difference in the rate of anastomotic leak comparing both anastomotic techniques. However, there are strong limitations to mention: variability of performed surgical procedures, stapler size, end-to-end $v s$. endto-side esophagogastric anastomosis, cervical $v s$. intrathoracic anastomosis, one-row $v s$. double-row anastomosis and application of neoadjuvant therapy prior to surgery. Our results show no significant differences concerning anastomotic leaks and strictures between both types of anastomosis, however both occurred less frequently (with a 50\% reduction) after stapler anastomosis. Moreover, we should also note that the 30-day mortality (often used in previous studies) underestimates in-hospital mortality. Our data also indicate that 90-day mortality more accurately represents the in-hospital mortality. The 90-day mortality was significantly reduced after stapler anastomosis ( $2 \%$ vs. $13.5 \%)$.

Simultaneous cholecystectomies were performed in the study period routinely, in order to avoid symptomatic gallstone formation later. Since 1947, it has been hypothesized that there is an increased rate for gallstone formation after gastric surgery ${ }^{[26]}$, as a result of resection of the anterior branch of the vagal nerve interrupting gallbladder innervation, thus disturbing gallbladder emptying and increasing cholecystokinin release ${ }^{[27-29]}$. Gillen et al. ${ }^{[30]}$ showed that the benefit of simultaneous cholecystectomy in the frame of gastric/esophageal resection does not outweigh the risks, thus not supporting the hypothesis of prophylactic cholecystectomy. This suggestion was based on the $6 \%$ incidence of acute/later cholecystectomy and the higher calculated additional morbidity of $0.95 \%$ compared with $0.45 \%{ }^{[30]}$. One out of the $176(0.005 \%)$ patients of our study group was submitted to redo surgery because of biliary leak after 


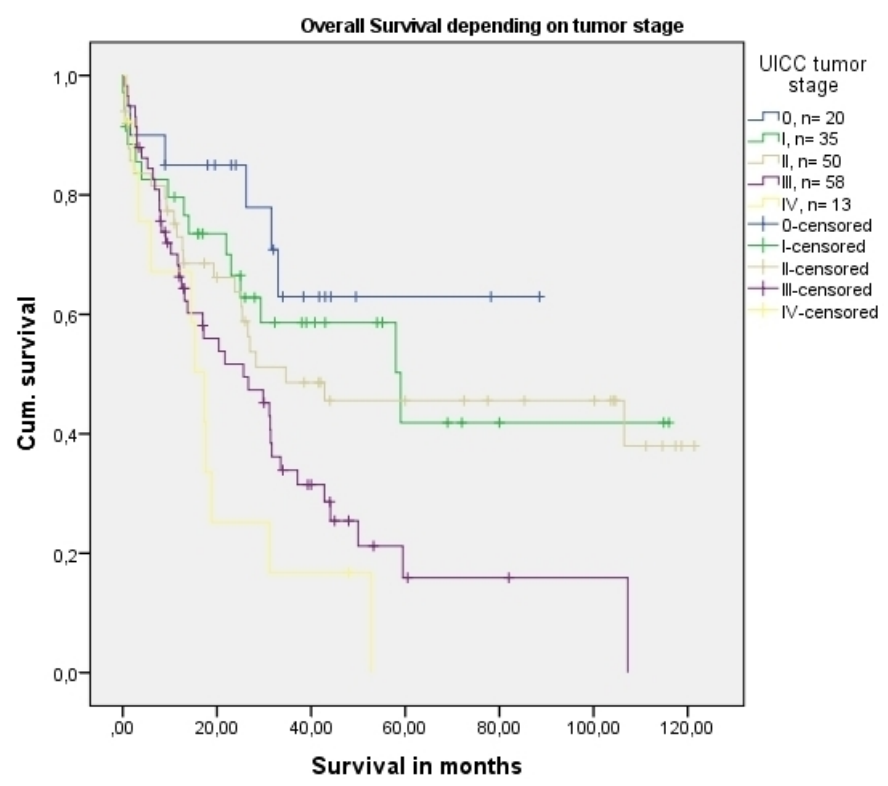

Figure 2. Cumulative survival after abdomino-thoracic esophageal resection with intrathoracic anastomosis for cancer depending upon UICC tumor stage $(P=0.001$, log rank test $)$.

prophylactic cholecystectomy in the frame of esophageal resection, thus not adding substantial morbidity.

The advantages of the present study are the qualitative homogeneity of the included patients and the thorough analysis of numerous parameters. We chose to include in the analysis only patients subjected to open Ivor-Lewis abdominothoracic esophageal resection with intrathoracic anastomosis. The therapeutic protocol used in our department is also standardized and given in detail. A thorough comparison of various parameters including intraoperative blood loss, duration of surgical procedure, number of reoperations, 30-, 60- and 90-day mortality and overall survival was performed.

The limitations of the present study are its retrospective, non-randomized character and the fact that the numbers of hand-sewn and stapler esophagogastric anastomoses are not equal (126 vs. 50). The management of anastomotic leaks changed during the different time periods, from being more aggressive (redo surgery) in the past to more conservative now (stent insertion), partially explaining the better postoperative outcome in the stapler anastomosis group.

In summary, the use of stapler to perform esophagogastric anastomosis and endoscopic stent insertion to manage anastomotic leak improved the postoperative outcome after abdominothoracic esophageal resection with intrathoracic anastomosis. In the current study, we experienced a lower anastomotic leaking rate and a better overall survival in favor of the group of patients who underwent a circular stapler anastomosis. Further improvement of surgical technique (minimally invasive surgical procedures) and better perioperative care protocols should further minimize anastomotic leaks after esophageal resections for cancer.

\section{DECLARATIONS}

\section{Acknowledgement}

Kolokotronis T and Galanis M would like to thank everyone who helped finalizing the project. Professor Dr. med. Matthias Glanemann, Head of Department, University Clinic of Saarland, Clinic for General, 
Visceral, Vascular, Pediatric and Transplantation Surgery, 66421 Homburg, Germany, is cordially thanked for providing supervision for Dr. T. Kolokotronis doctoral thesis and giving his permission to collect data.

\section{Authors' contributions}

The first author: Kolokotronis T

The last author: Galanis M

\section{Availability of data and materials}

Not applicable.

\section{Financial support and sponsorship}

None.

\section{Conflicts of interest}

Both authors declared that there are no conflicts of interest.

\section{Ethical approval and consent to participate}

This publication is part of the doctoral thesis of Kolokotronis T with the title: "Postoperative outcome and overall survival after surgery for esophageal cancer; a retrospective, single- center experience of 320 patients encompassing 14 years".

\section{Consent for publication}

Not applicable.

\section{Copyright}

(c) The Author(s) 2021.

\section{REFERENCES}

1. Vigneswaran WT, Trastek VF, Pairolero PC, Deschamps C, Daly RC, Allen MS. Transhiatal esophagectomy for carcinoma of the esophagus. Ann Thorac Surg 1993;56:838-44; discussion 44. DOI

2. Agrawal S, Deshmukh SP, Patil PK, et al. Intrathoracic anastomosis after oesophageal resection for cancer. J Surg Oncol 1996;63:526. DOI PubMed

3. Ercan S, Rice TW, Murthy SC, Rybicki LA, Blackstone EH. Does esophagogastric anastomotic technique influence the outcome of patients with esophageal cancer? J Thorac Cardiovasc Surg 2005;129:623-31. DOI PubMed

4. Martin LW, Swisher SG, Hofstetter W, et al. Intrathoracic leaks following esophagectomy are no longer associated with increased mortality. Ann Surg 2005;242:392-9; discussion 9. DOI PubMed PMC

5. Urschel JD, Blewett CJ, Bennett WF, Miller JD, Young JE. Handsewn or stapled esophagogastric anastomoses after esophagectomy for cancer: meta-analysis of randomized controlled trials. Dis Esophagus 2001;14:212-7. DOI PubMed

6. Kassis ES, Kosinski AS, Ross P Jr. , Koppes KE, Donahue JM, Daniel VC. Predictors of anastomotic leak after esophagectomy: an analysis of the society of thoracic surgeons general thoracic database. Ann Thorac Surg 2013;96:1919-26. DOI

7. Goense L, van Rossum PSN, Weijs TJ, et al. Aortic Calcification Increases the Risk of Anastomotic Leakage After Ivor-Lewis Esophagectomy. Ann Thorac Surg 2016;102:247-52. DOI PubMed

8. Michelet P, D'Journo XB, Roch A, et al. Perioperative risk factors for anastomotic leakage after esophagectomy: influence of thoracic epidural analgesia. Chest 2005;128:3461-6. DOI PubMed

9. Schilling M, Buchler MW. Fundus rotation gastroplasty. Dig Surg 1999;16:175-7. DOI PubMed

10. Gooszen JAH, Goense L, Gisbertz SS, Ruurda JP, van Hillegersberg R, van Berge Henegouwen MI. Intrathoracic versus cervical anastomosis and predictors of anastomotic leakage after oesophagectomy for cancer. Br J Surg 2018;105:552-60. DOI PubMed PMC

11. Klink CD, Binnebosel M, Otto J, et al. Intrathoracic versus cervical anastomosis after resection of esophageal cancer: a matched pair analysis of 72 patients in a single center study. World J Surg Oncol 2012;10:159. DOI PubMed PMC

12. Ribet M, Debrueres B, Lecomte-Houcke M. Resection for advanced cancer of the thoracic esophagus: cervical or thoracic anastomosis? J Thorac Cardiovasc Surg 1992;103:784-9. PubMed

13. Walther B, Johansson J, Johnsson F, Von Holstein CS, Zilling T. Cervical or thoracic anastomosis after esophageal resection and gastric tube reconstruction: a prospective randomized trial comparing sutured neck anastomosis with stapled intrathoracic anastomosis. Ann Surg 2003;238:803-12; discussion 12. DOI PubMed PMC

14. Okuyama M, Motoyama S, Suzuki H, Saito R, Maruyama K, Ogawa J. Hand-sewn cervical anastomosis versus stapled intrathoracic 
anastomosis after esophagectomy for middle or lower thoracic esophageal cancer: a prospective randomized controlled study. Surg Today 2007;37:947-52. DOI PubMed

15. Ravitch MM, Steichen FM. A stapling instrument for end-to-end inverting anastomoses in the gastrointestinal tract. Ann Surg 1979;189:791-7. DOI PubMed PMC

16. Hopkins RA, Alexander JC, Postlethwait RW. Stapled esophagogastric anastomosis. Am J Surg 1984;147:283-7. DOI PubMed

17. Beitler AL, Urschel JD. Comparison of stapled and hand-sewn esophagogastric anastomoses. Am J Surg 1998;175:337-40. DOI PubMed

18. Yanni F, Singh P, Tewari N, et al. Comparison of Outcomes with Semi-mechanical and Circular Stapled Intrathoracic Esophagogastric Anastomosis following Esophagectomy. World J Surg 2019;43:2483-9. DOI PubMed

19. Lewis I. The surgical treatment of carcinoma of the oesophagus; with special reference to a new operation for growths of the middle third. Br J Surg 1946;34:18-31. DOI PubMed

20. Hartwig W, Strobel O, Schneider L, et al. Fundus rotation gastroplasty vs. Kirschner-Akiyama gastric tube in esophageal resection: comparison of perioperative and long-term results. World J Surg 2008;32:1695-702. DOI PubMed

21. Akiyama H, Hiyama M, Hashimoto C. Resection and reconstruction for carcinoma of the thoracic oesophagus. Br J Surg 1976;63:2069. DOI PubMed

22. Dindo D, Demartines N, Clavien PA. Classification of surgical complications: a new proposal with evaluation in a cohort of 6336 patients and results of a survey. Ann Surg 2004;240:205-13. DOI PubMed PMC

23. Stahl M, Mariette C, Haustermans K, Cervantes A, Arnold D, Group EGW. Oesophageal cancer: ESMO Clinical Practice Guidelines for diagnosis, treatment and follow-up. Ann Oncol 2013;24 Suppl 6:vi51-6. DOI PubMed

24. Kim RH, Takabe K. Methods of esophagogastric anastomoses following esophagectomy for cancer: A systematic review. J Surg Oncol 2010;101:527-33. DOI PubMed

25. Law S, Fok M, Chu KM, Wong J. Comparison of hand-sewn and stapled esophagogastric anastomosis after esophageal resection for cancer: a prospective randomized controlled trial. Ann Surg 1997;226:169-73. DOI PubMed PMC

26. Majoor CL, Suren TJ. Gall-bladder complications following resection of the stomach for peptic ulcer. Br Med J 1947;2:8-11. DOI PubMed PMC

27. Pellegrini CA, Lewin M, Patti MG, Thomas MJ, Ryan T, Way LW. Gallbladder filling and response to cholecystokinin are not affected by vagotomy. Surgery 1985;98:452-8. PubMed

28. Yi SQ, Ohta T, Tsuchida A, et al. Surgical anatomy of innervation of the gallbladder in humans and Suncus murinus with special reference to morphological understanding of gallstone formation after gastrectomy. World J Gastroenterol 2007;13:2066-71. DOI PubMed PMC

29. Parkin GJ, Smith RB, Johnston D. Gallbladder volume and contractility after truncal, selective and highly selective (parietal-cell) vagotomy in man. Ann Surg 1973;178:581-6. DOI PubMed PMC

30. Gillen S, Michalski CW, Schuster T, Feith M, Friess H, Kleeff J. Simultaneous/Incidental cholecystectomy during gastric/esophageal resection: systematic analysis of risks and benefits. World J Surg 2010;34:1008-14. DOI PubMed 